(2rossMark

Cite this: Dalton Trans., 2015, 44 11278

Received 11th May 2015, Accepted 18th May 2015

DOI: $10.1039 / c 5 d t 01775 k$

www.rsc.org/dalton

\section{Introducing a pyrazole/imidazole based hybrid cyclophane: a hydrogen bond sensor and binucleating ligand precursor $\dagger$}

\author{
Philipp J. Altmann, Christian Jandl and Alexander Pöthig*
}

\begin{abstract}
A novel cyclophane consisting of methylene-bridged imidazoliumand pyrazole-moieties (calix[4]imidazolium[2]pyrazole) and two of its applications are presented. First, supramolecular recognition of an acetonitrile molecule by hydrogen bonding in the solid state is examined. Second, the capability to act as a ligand precursor is shown by the synthesis and characterisation of the respective dinuclear NHC-nickel(II) complex.
\end{abstract}

Macrocyclic poly-NHC ligands are the focus of current research. ${ }^{1}$ Very recently, cyclophanes featuring exclusively alkylene bridged NHC moieties have been successfully applied in the respective iron complexes, ${ }^{2}$ which showed high stability and reactivity e.g. towards oxygen and $\mathrm{CH}$ activation. Furthermore, their respective ligand precursors are excellent receptors for anion binding due to the remarkable hydrogen bond donor abilities of the acidic imidazolium moieties. ${ }^{3}$ Various macrocyclic imidazolium $/ N$-donor hybrid systems have also been shown to function as NHC ligand precursors and $\mathrm{H}$-bond donors. ${ }^{1 a, 4}$ For open-chain poly-NHC ligands, the introduction of a pyrazole-bridge between two NHC moieties allowed for the synthesis of dinuclear complexes of a variety of transition metals; ${ }^{5}$ the respective $\mathrm{Cu}^{6}$ and $\mathrm{Ru}^{5 c}$ complexes showed electronic coupling through the ligand which enabled access to intermediate oxidation states, a feature that is crucial for specific catalytic reactions.

Our presented approach combines the concept of macrocyclic poly-NHCs with that of bridging pyrazole moieties. The resulting macrocycle is both capable of acting as a multiple hydrogen bond donor and, upon deprotonation, of coordinating two metal centres in close proximity within a rigid framework. For this purpose, we first improved the accessibility of the literature-known pyrazole-bridge precursor $2,{ }^{7}$ which was subsequently treated with sodium imidazolide to yield bisimid-

Catalysis Research Center \& Department of Chemistry, Technische Universität München, Ernst-Otto-Fischer-Str. 1, 85747 Garching bei München, Germany. E-mail: alexander.poethig@tum.de

$\dagger$ Electronic supplementary information (ESI) available. CCDC 1057574-1057576. For ESI and crystallographic data in CIF or other electronic format see DOI: $10.1039 / \mathrm{c} 5 \mathrm{dt} 01775 \mathrm{k}$

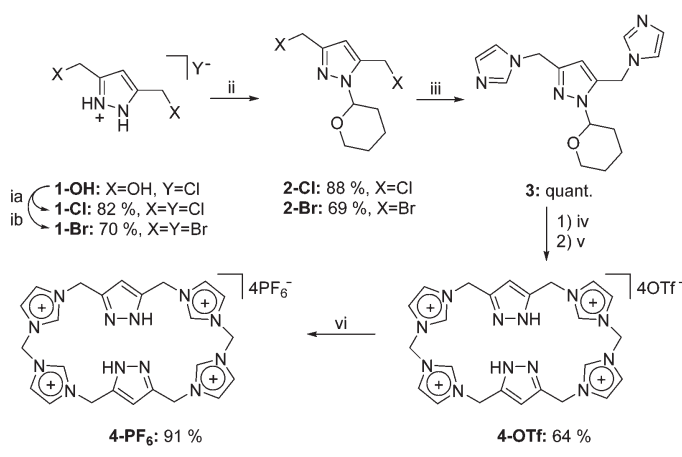

Scheme 1 Synthesis of hydrogen bond donors 4-OTf and 4-PF $\mathrm{SOCl}_{2}$ (neat), $95{ }^{\circ} \mathrm{C}, 30 \mathrm{~min}$; (ib) $\mathrm{SOBr}_{2}$ (neat), 0-40 ${ }^{\circ} \mathrm{C}, 2 \mathrm{~h}$; (ii) 3,4dihydro-2H-pyran, (DCM), r.t., $16 \mathrm{~h}$; (iii) $\mathrm{Nalm}$, (MeCN), r.t., $16 \mathrm{~h}$; (iv) $\mathrm{Me}(\mathrm{OTf})_{2}$, (MeCN), $-40{ }^{\circ} \mathrm{C}$-r.t., $16 \mathrm{~h}$; (v) $\mathrm{Tf}_{2} \mathrm{O} / \mathrm{H}_{2} \mathrm{O}$, (EtOH), r.t., $30 \mathrm{~min}$; (vi) $\mathrm{NH}_{4} \mathrm{PF}_{6},\left(\mathrm{H}_{2} \mathrm{O}\right)$, r.t., $30 \mathrm{~min}$.

azole 3 (Scheme 1, for experimental details, see the ESI $\dagger$ ). The latter then underwent a macrocyclisation protocol utilising methylene bistriflate, ${ }^{2 b}$ leading to a mixture of differently sized macrocycles, from which ligand precursor $\mathbf{4}-\mathbf{P F}_{\mathbf{6}}$ was selectively isolated after workup and subsequent anion exchange. The ${ }^{1} \mathrm{H}$ NMR spectra of both $\mathbf{4}$-OTf and $\mathbf{4}^{\mathbf{4}}-\mathbf{P F}_{6}$ suggest an overall symmetric behaviour in DMSO solution as only one set of signals was observable for chemically equivalent protons. In the case of $\mathbf{4}-\mathbf{P F}_{\mathbf{6}}$ exactly one equivalent of acetonitrile was found to be present in the thoroughly dried sample as verified by elemental analysis and NMR spectroscopy (Fig. 1). Elemental analysis further proved the existence of four anions and therefore the neutral charge of the pyrazole moieties in both compounds. Mass spectra of 4-OTf and $\mathbf{4 - \mathbf { P F } _ { 6 }}$ solely feature signals for combinations of the macrocycle in different protonation states of the pyrazoles and the counterions $\mathrm{PF}_{6}{ }^{-}$and $\mathrm{OTf}^{-}$, respectively. Single crystals of 4-OTf and $\mathbf{4}-\mathbf{P F}_{6}$ suitable for diffraction analysis were grown by slow diffusion of diethyl ether into a solution in acetonitrile. The solid state structures of the cyclophane are shown in Fig. 2. 


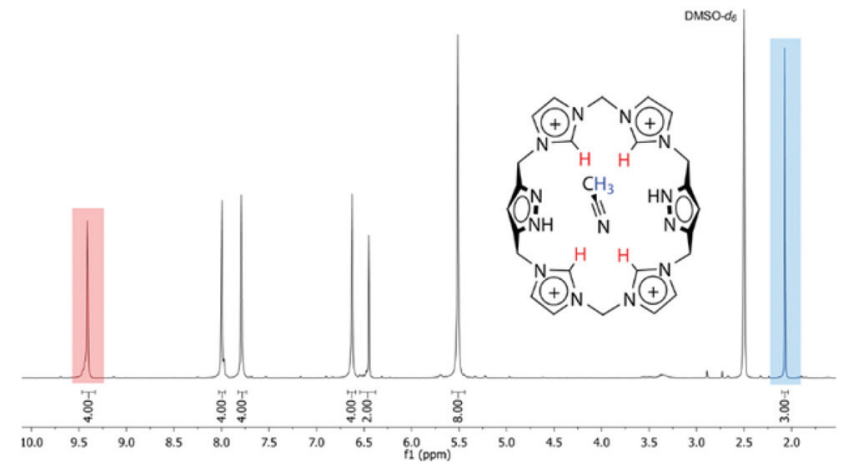

Fig. $1{ }^{1} \mathrm{H}$ NMR spectrum of $4-\mathrm{PF}_{6}$ containing exactly one equivalent of $\mathrm{MeCN}$.
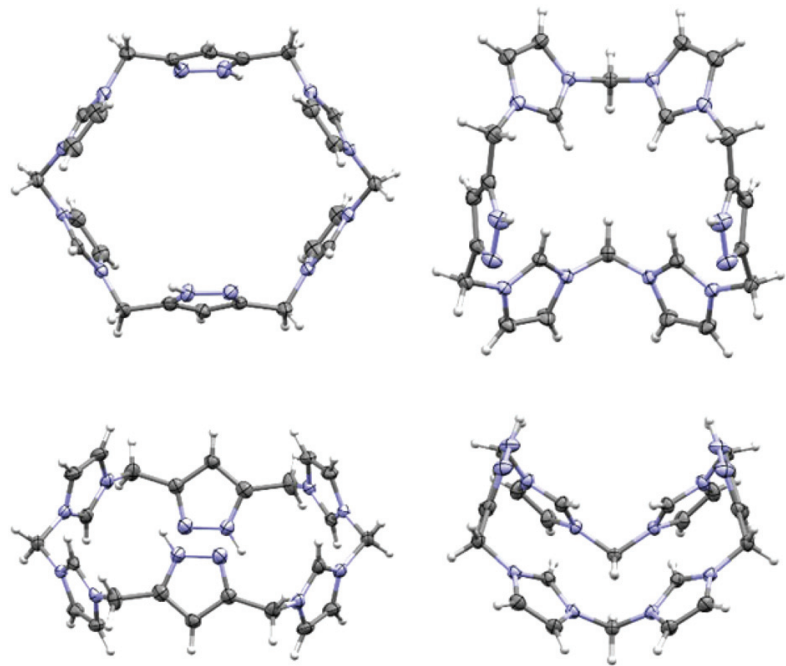

Fig. 2 Different conformations of 4 in the solid state (top and side perspectives). Ellipsoids are shown at $50 \%$ probability. Counterions and solvent molecules are omitted for clarity. Left: molecular structure of the cation of 4-OTf showing an unstrained conformation of alternatingly oriented five-membered heterocycles (one out of two independent molecules of the asymmetric unit is shown). Right: molecular structure of the cation of $4-\mathrm{PF}_{6}$ showing a strained bowl-shape conformation.

The simple anion exchange has a tremendous effect on the molecular structure of $\mathbf{4}$ in the crystal. Whereas in 4-OTf the cation forms almost perfectly unstrained hexagons with alternatingly oriented five-membered rings (Fig. 2, left), in $\mathbf{4}-\mathbf{P F}_{\mathbf{6}}$ the conformation changes drastically producing a bowl-shaped cavity (Fig. 2, right). As expected, Hirshfeld analysis ${ }^{8}$ of the cations shows that the majority of interactions in both compounds originate from $\mathrm{H}$-atoms of 4 interacting with $\mathrm{H}$-bond acceptors $(77 \%$, see the ESI $\dagger$ ). In the case of 4-OTf the $\mathrm{H} \cdots \mathrm{O}$ contacts to different triflate anions can be assigned as the dominant interaction (37\%), followed by less directed $\mathrm{H} \cdots \mathrm{F}$ contacts $(22 \%)$. This way, all different types of $\mathrm{H}$-atoms, namely those at the imidazolium, pyrazole and methylene bridge moieties, are involved in these contacts and do not show a systematic tendency towards specific acceptor atoms.

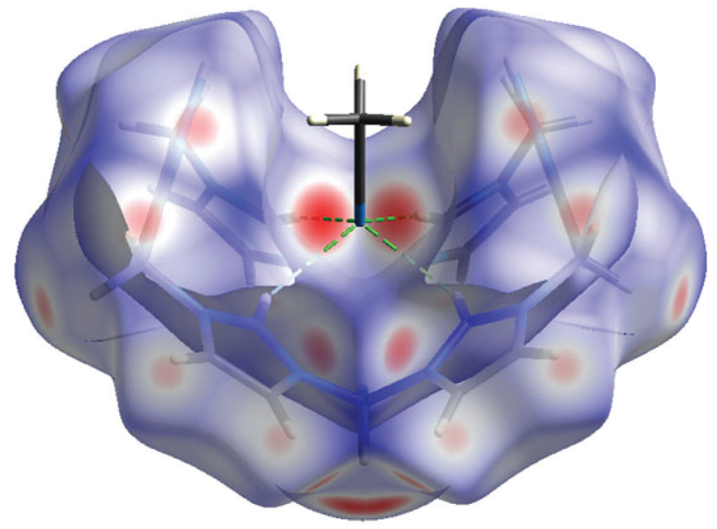

Fig. 3 Supramolecular recognition of $\mathrm{MeCN}$ by the cation of $4-\mathrm{PF}_{6}$ in the solid state shown by Hirshfeld surface analysis. ${ }^{8}$ Directed hydrogen bonding (green) from all four imidazolium $\mathrm{C} 2$ protons towards a $\mathrm{MeCN}$ nitrogen acceptor.

By contrast, for $\mathbf{4}-\mathbf{P F}_{\mathbf{6}}$ a strong selectivity of the different protons towards the acceptors can be observed in the crystal structure. The C2-protons of all four imidazolium moieties are selectively pointing towards the nitrogen atom of an

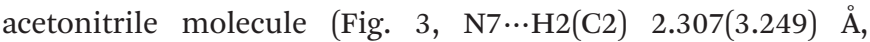

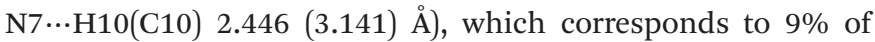
the interaction of the cation with other molecules. Consequently, the acetonitrile molecule perfectly fits into the cavity, rationalising why one equivalent of the solvent could not be removed in vacuo.

The biggest share consists of $\mathrm{H} \cdots \mathrm{F}$ contacts to the $\mathrm{PF}_{6}{ }^{-}$ anions (49\%), which are formed by the pyrazole, the methylene bridge and the backbone protons of the imidazolium units. This hydrogen bonding may stabilise the bowl shaped conformation of the cation of $\mathbf{4}-\mathbf{P F}_{\mathbf{6}}$, which is less stable by $28.5 \mathrm{kcal} \mathrm{mol}^{-1}$ in the gas phase compared to the unstrained conformation in 4-OTf according to single-point DFT calculations. This is a remarkable difference certainly caused by the repulsive Coulomb interactions in the bowl-shaped conformation of the highly charged macrocycle. However, in the solid state, this intramolecular repulsive effect apparently is overcompensated by attractive interactions with the anions and acetonitrile molecules, such that this conformation can be experimentally observed. The fact that both $\mathbf{4 - O T f}$ and $\mathbf{4}-\mathbf{P F}_{\mathbf{6}}$ were crystallised from the same solvent mixtures underlines the effect of the counterion. At the moment, we are systematically evaluating the influence of other anions and solvents and whether a recognition of hydrogen bond acceptors can also be observed in the liquid phase.

We further tested whether the $N$-heterocyclic moieties can be deprotonated and subsequently coordinated to a set of two metal centres. Out of the different metalation strategies, we chose the reaction with a metal precursor upon deprotonation by an external base. Treatment of $\mathbf{4}-\mathbf{P F}_{\mathbf{6}}$ with caesium carbonate in the presence of bis(triphenylphosphine)nickel(II) chloride produced the dinuclear $\mathrm{Ni}$ complex $\mathbf{5}-\mathbf{P F}_{\mathbf{6}}$ which was obtained in good yields after workup (Scheme 2). The overall 


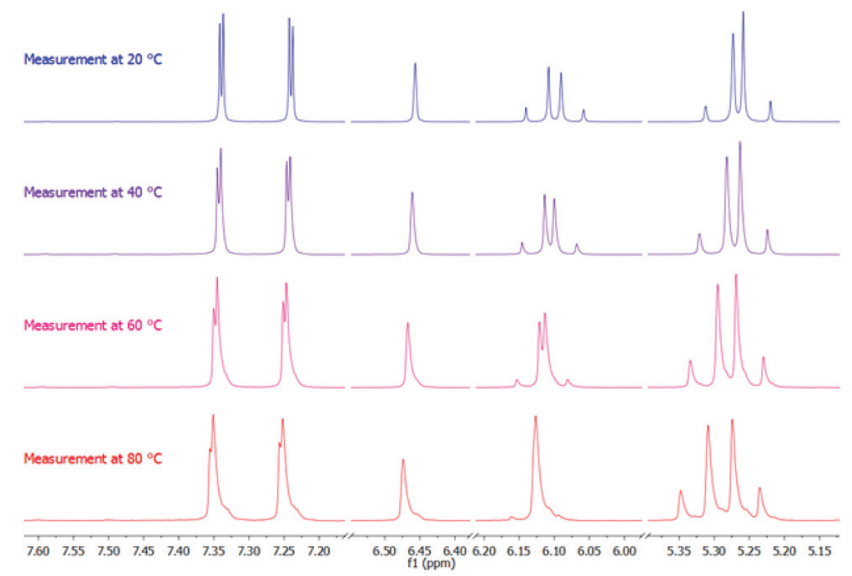

Fig. 4 Variable temperature ${ }^{1} \mathrm{H}$ NMR spectra of dinuclear complex $5-\mathrm{PF}_{6}$ (blank areas are left out intentionally for clarity; for full spectra see the ESI $\dagger$ ). No significant change of the signal shapes at high temperatures is observable, suggesting a rigid ligand framework.

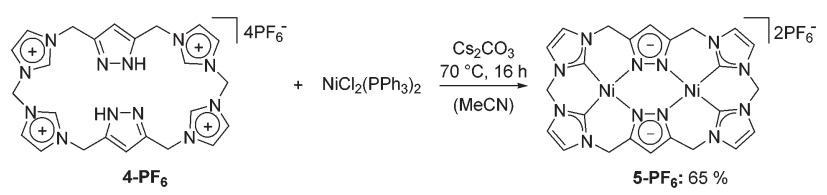

Scheme 2 Synthesis of dinuclear NHC-nickel(I) complex 5-PF 6 .

yield of $\mathbf{5}-\mathbf{P F}_{\mathbf{6}}$ for the multistep synthesis starting from 1-OH is up to $27 \%$ for the $\mathbf{1}-\mathbf{C l}$ route. Compound $\mathbf{5}-\mathbf{P F}_{\mathbf{6}}$ gives rise to seven independent sets of signals in the ${ }^{1} \mathrm{H}$ NMR spectrum (see the ESI + ). Most notable is the splitting of the protons of the bridging methylene groups indicating a reduction of the molecular symmetry in solution compared to 4-PF $\mathbf{F}_{6}$. No change of the signal shapes was observed up to $80{ }^{\circ} \mathrm{C}$ suggesting an overall rigid and robust ligand framework (Fig. 4). As expected, the ${ }^{13} \mathrm{C}$ NMR spectrum exhibits seven signals (see the ESI†).

Interestingly, the carbene carbon resonance at $157.6 \mathrm{ppm}$ appears as a rather intense signal, which is unusual because of the commonly poor relaxation processes for carbene carbon atoms. This finding might point towards cooperative electronic effects involving the two $\mathrm{Ni}$ (II) centres connected via the pyrazolate moieties. The mass spectrum of $\mathbf{5}-\mathbf{P F}_{\mathbf{6}}$ shows two characteristic signals, one at $m / z=297.4$ for $\left(5-\mathbf{P F}_{6}-2 \mathrm{PF}_{6}{ }^{-2+}\right.$ and the other at 739.2 for $\left(\mathbf{5}-\mathbf{P F}_{6}-\mathbf{P F}_{6}{ }^{-}\right)^{+}$. Furthermore, the elemental analysis indicates the presence of two equivalents of hexafluorophosphate anions per macrocycle, further supporting the sixfold deprotonation of the ligand precursor during the synthesis.

Single crystals suitable for X-ray diffraction were grown by slow diffusion of diethyl ether into a solution in dimethyl formamide. The molecular structure of $\mathbf{5}-\mathbf{P F}_{\mathbf{6}}$ is shown in Fig. 5 and is in accordance with the results obtained by prior analysis

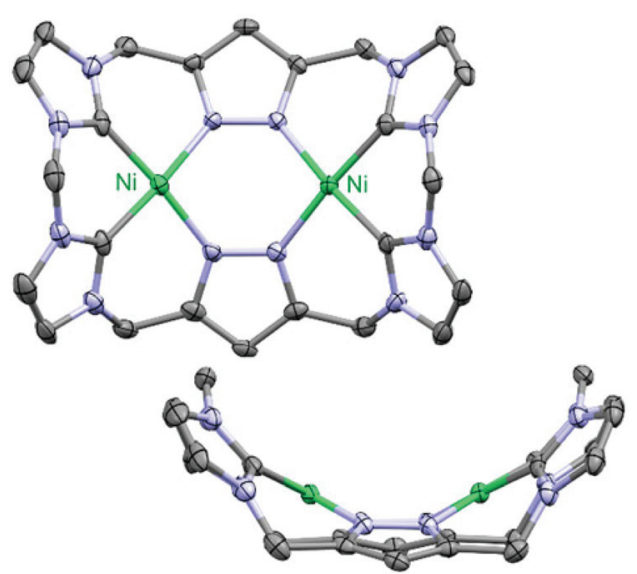

Fig. 5 Solid state structure of dinuclear complex 5-PF . View from two perspectives showing the bowl-shaped arrangement of the complex. The asymmetric unit contains two fragments out of which one was chosen. ADPs are shown at the 50\% probability level, and hydrogen atoms and hexafluorophosphate counterions are omitted for clarity.

methods. The two nickel ions are coordinated in a slightly distorted square planar fashion by two $\mathrm{C}_{\text {carbene }}$ and two $\mathrm{N}$ donors each. The Ni-C bond lengths between 1.844(4) and 1.870(4) $\AA$ (two molecules in the asymmetric unit) are within literaturereported values and a little shorter than the $\mathrm{Ni}-\mathrm{N}$ bonds of 1.897(3)-1.912(3) $\AA^{16,5 b, 9}$ In addition, the $\mathrm{C}-\mathrm{Ni}-\mathrm{C}$ angles $\left(85.4(2)-86.7(2)^{\circ}\right)$ are smaller than the $\mathrm{N}-\mathrm{Ni}-\mathrm{N}$ angles (94.4(1)$\left.95.0(1)^{\circ}\right)$. The molecular structure is best described as bowlshaped with the pyrazolate rings at the bottom and the NHC moieties bent upwards to each side which places the two Ni ions at distances of 3.5957(8) and 3.6043(8) ^, respectively. The two mean planes established by each $\mathrm{Ni}$ ion and its coordinating atoms form opening angles of $122-123^{\circ}$ which leaves wide open cavities occupied by hexafluorophosphate ions in the solid state.

The bowl-shaped structure perfectly explains the splitting pattern in the NMR spectra. In addition, the rather rigid structure causes the protons in the bridges to split up as there is no possibility of a ring flip in the complex that would result in magnetically equivalent protons in solution. The bent structure of the complex forms promising binding pockets for small molecules that might facilitate their activation after reducing the complex chemically or electrochemically. Similar reactivities have recently been demonstrated for mononuclear nickel NHC and non-NHC complexes. ${ }^{10}$

The presented results are the fundamentals of a divergent chemistry, which we are currently pursuing. First, the promising hydrogen bond donor (and acceptor) capabilities of cation $\mathbf{4}$ towards acetonitrile will be further evaluated by applying a variety of other hydrogen bond acceptors. Second, Ni complex $\mathbf{5}-\mathbf{P F}_{6}$ as the first example of an $\mathbf{N H C}$ complex bearing this macrocyclic ligand is a promising molecular catalyst for several catalytic transformations and will therein be tested and characterised in greater detail. Lastly, we aim at expanding the scope of the ligand by applying it to other (transition) metals 
and intensively studying its coordination chemistry and the properties of the resulting complexes.

\section{Acknowledgements}

We thank Prof. W. A. Herrmann and Prof. F. E. Kühn for their mentorship and support. The CRC, the Faculty of Chemistry (TUM) as well as the Fonds der Chemischen Industrie (FCI, Sachkostenzuschuss A.P.) are very much acknowledged for funding this work. Tobias Schirmer is acknowledged for practical support.

\section{Notes and references}

1 (a) P. G. Edwards and F. E. Hahn, Dalton Trans., 2011, 40, 10278 and references cited therein; (b) Z. Lu, S. A. Cramer and D. M. Jenkins, Chem. Sci., 2012, 3, 3081; (c) C. Schulte to Brinke, T. Pape and F. E. Hahn, Dalton Trans., 2013, 42, 7330.

2 (a) S. Meyer, I. Klawitter, S. Demeshko, E. Bill and F. Meyer, Angew. Chem., Int. Ed., 2013, 52, 901; (b) M. R. Anneser, S. Haslinger, A. Pöthig, M. Cokoja, J.-M. Basset and F. E. Kühn, Inorg. Chem., 2015, 54, 3797.

3 (a) H.-Y. Gong, B. M. Rambo, E. Karnas, V. M. Lynch and J. L. Sessler, Nat. Chem., 2010, 2, 406; (b) C. J. Serpell, J. Cookson, A. L. Thompson and P. D. Beer, Chem. Sci., 2011, 2, 494; (c) Y. Chun, N. J. Singh, I. C. Hwang, J. W. Lee, S. U. Yu and K. S. Kim, Nat. Commun., 2013, 4, 1797.
4 I. Klawitter, M. R. Anneser, S. Dechert, S. Meyer, S. Demeshko, S. Haslinger, A. Pöthig, F. E. Kühn and F. Meyer, Organometallics, 2015, DOI: 10.1021/acs. organomet.5b00103.

5 (a) U. J. Scheele, M. John, S. Dechert and F. Meyer, Eur. J. Inorg. Chem., 2008, 373; (b) Y. Zhou, Z. Xi, W. Chen and D. Wang, Organometallics, 2008, 27, 5911; (c) S. A. Reindl, A. Pöthig, M. Drees, B. Bechlars, E. Herdtweck, W. A. Herrmann and F. E. Kühn, Organometallics, 2013, 32, 4082.

6 B. Liu, B. Liu, Y. Zhou and W. Chen, Organometallics, 2010, 29, 1457.

7 (a) J. C. Röder, F. Meyer, M. Konrad, S. Sandhöfner, E. Kaifer and H. Pritzkow, Eur. J. Org. Chem., 2001, 4479; (b) J. C. Röder, F. Meyer and H. Pritzkow, Organometallics, 2001, 20, 811.

8 M. A. Spackman and D. Jayatilakaa, CrystEngComm, 2009, 11, 19.

9 (a) M. V. Baker, B. W. Skelton, A. H. White and C. C. Williams, Organometallics, 2002, 21, 2674; (b) H. M. Bass, S. A. Cramer, A. S. McCullough, K. J. Bernstein, C. R. Murdock and D. M. Jenkins, Organometallics, 2013, 32, 2160.

10 (a) N. J. Findlay, S. R. Park, F. Schoenebeck, E. Cahard, S.-Z. Zhou, L. E. A. Berlouis, M. D. Spicer, T. Tuttle and J. A. Murphy, J. Am. Chem. Soc., 2010, 132, 15462; (b) J. D. Froehlich and C. P. Kubiak, Inorg. Chem., 2012, 51, 3932; (c) M. H. Reineke, M. D. Sampson, A. L. Rheingold and C. P. Kubiak, Inorg. Chem., 2015, 54, 3211. 